\title{
Including the sub-grid scale plume rise of vegetation fires in low resolution atmospheric transport models
}

\author{
S. R. Freitas ${ }^{1}$, K. M. Longo ${ }^{1}$, R. Chatfield ${ }^{2}$, D. Latham ${ }^{3}$, M. A. F. Silva Dias ${ }^{1,7}$, M. O. Andreae ${ }^{4}$, E. Prins ${ }^{5}$, \\ J. C. Santos ${ }^{6}$, R. Gielow ${ }^{1}$, and J. A. Carvalho Jr. ${ }^{8}$ \\ ${ }^{1}$ Center for Weather Forecasting and Climate Studies, INPE, Cachoeira Paulista, Brazil \\ ${ }^{2}$ NASA Ames Research Center, Moffet Field, USA \\ ${ }^{3}$ USDA Forest Service, Montana, USA \\ ${ }^{4}$ Max Planck Institute for Chemistry, Mainz, Germany \\ ${ }^{5}$ UW-Madison Cooperative Institute for Meteorological Satellite Studies, Madison, WI, USA \\ ${ }^{6}$ Laboratório de Combustão e Propulsão, INPE, Cachoeira Paulista, Brazil \\ ${ }^{7}$ Department of Atmospheric Sciences, University of São Paulo, Brazil \\ ${ }^{8}$ FEG/UNESP, Guaratinguetá, SP, Brazil
}

Received: 30 October 2006 - Published in Atmos. Chem. Phys. Discuss.: 17 November 2006

Revised: 5 June 2007 - Accepted: 20 June 2007 - Published: 2 July 2007

\begin{abstract}
We describe and begin to evaluate a parameterization to include the vertical transport of hot gases and particles emitted from biomass burning in low resolution atmosphericchemistry transport models. This sub-grid transport mechanism is simulated by embedding a 1-D cloud-resolving model with appropriate lower boundary conditions in each column of the 3-D host model. Through assimilation of remote sensing fire products, we recognize which columns have fires. Using a land use dataset appropriate fire properties are selected. The host model provides the environmental conditions, allowing the plume rise to be simulated explicitly. The derived height of the plume is then used in the source emission field of the host model to determine the effective injection height, releasing the material emitted during the flaming phase at this height. Model results are compared with CO aircraft profiles from an Amazon basin field campaign and with satellite data, showing the huge impact that this mechanism has on model performance. We also show the relative role of each main vertical transport mechanisms, shallow and deep moist convection and the pyro-convection (dry or moist) induced by vegetation fires, on the distribution of biomass burning $\mathrm{CO}$ emissions in the troposphere.
\end{abstract}

Correspondence to: S. R. Freitas

(sfreitas@cptec.inpe.br)

\section{Introduction}

The high concentrations of aerosol particles and trace gases observed in the Amazon and Central Brazilian atmosphere during the dry season are associated with intense anthropogenic biomass burning activity (vegetation fires, Andreae, 1991). Most of the particles are in the fine particle fraction of the size distribution, which can remain in the atmosphere for approximately a week (Kaufman, 1995; Reid et al., 2005). In addition to aerosol particles, biomass burning produces water vapor and carbon dioxide $\left(\mathrm{CO}_{2}\right)$, and is a major source of other compounds such as carbon monoxide $(\mathrm{CO})$, volatile organic compounds, nitrogen oxides $\left(\mathrm{NO}_{\mathrm{x}}=\mathrm{NO}+\mathrm{NO}_{2}\right)$ and organic halogen compounds. In the presence of abundant solar radiation and high concentrations of $\mathrm{NO}_{\mathrm{x}}$, the oxidation of $\mathrm{CO}$ and hydrocarbons typically causes ozone $\left(\mathrm{O}_{3}\right)$ formation.

In spite of the continuous increase in computing power, we are still far from the capability of running atmospheric models, whether including chemistry or not, that take into account explicitly all relevant motion scales. Therefore, current atmospheric chemistry models use several types of parameterizations in order to include the sub-grid processes to resolve the mass continuity equation of the transported species. The most common sub-grid transport parameterizations include diffusion in the boundary layer and convective transport associated with moist convection. However, for biomass

Published by Copernicus Publications on behalf of the European Geosciences Union. 
burning emissions the strong updrafts associated with the initial buoyancy can have a huge impact on tracer distribution through a direct and rapid transport into the free troposphere as well as the stratosphere (Fromm et al., 2000; Fromm and Servranckx, 2003; Jost et al., 2004; Rosenfeld et al., 2007). This mechanism cannot be resolved explicitly by the current large-scale models and it is frequently ignored. However, Liousse et al. (1996) in their global model studies of carbonaceous aerosols, showed that the predicted concentrations in remote areas are extremely dependent on the height of injection of the aerosols, among others factors. Chatfield and Delany (1990) and Poppe et al. (1998) demonstrated that due to the nonlinearity of ozone production, the rate of ozone formation is influenced by atmospheric dilution and transport. Consequently, the plume rise mechanism plays an important role. In the absence of this mechanism, the pyrogenic emissions often are released at the surface in the model, or vertically distributed in an arbitrary way (Turquety et al., 2007) or using some empirical relationship between the injection height and fire intensity (Lavoué et al., 2000; Wang et al, 2006).

Several authors presented work on numerical simulation of smoke transport associated with urban, wildland and slash fires. Penner et al. (1986) performed simulations of smoke distribution above large fires using a compressible and nonhydrostatic model including water vapor condensation. The authors found that the height of smoke depends on the environmental conditions (stability, the amount the water vapor and the wind speeds), as well as the heat flux. Similar results were also found by Small and Heikes (1988). However, for small fires (radius $<1 \mathrm{~km}$ ) Heikes et al. (1990) found that the plume rise is mostly controlled by total heat release (the heat flux spatially integrated) and by the entrainment of environmental air into the plume. Trentmann et al. (2002, hereafter T2002) applied the ATHAM plume model successfully to simulate the dynamical evolution of the plume from the Quinault prescribed fire on the Pacific Coast of Washington State (USA). The fire burned 19.4 ha with maximum convective heat flux around $3 \mathrm{GW}$. The ATHAM model reproduced quite well the injection height (250-600 m above the surface in a stable maritime influenced flow) and the horizontal extent of the plume $(\sim 4 \mathrm{~km})$. More recently, Luderer et al. (2006) and Trentmann et al. (2006) used the ATHAM model to perform 3-D simulations and sensitivity studies on the smoke injection into the lower stratosphere by the Chisholm forest fire in Canada in May 2001. Coupled atmosphere-fire models have been proposed by several authors (Clark et al., 1996; Grishin, 1996; Clark et al., 2003) and include detailed interaction between the atmosphere and combusting material. However, these models have the enormous task of taking into account all the relevant spatial scales, which span six to seven orders of magnitude (Clark et al., 2003).

From the observational point of view, Carvalho et al. (1995) measured air temperature above a tropical rainforest clearing fire experiment in Brazil. The authors burned an area of $1 \mathrm{ha}$ and the flaming phase lasted about $2 \mathrm{~h}$. The maximum temperatures recorded by three radiation-shielded thermocouples installed at the levels 8,12 and $20 \mathrm{~m}$ above ground level (AGL) were about 328-333 K during the flaming combustion, only $20-25 \mathrm{~K}$ warmer than the environmental air. Using the carbon flux estimated by the authors, the mean heat flux from the fires was about $28 \mathrm{~kW} \mathrm{~m}^{-2}$. Riggan et al. (2004) describe temperature, vertical velocity, sensible heat and radiative fluxes, among other properties in plumes from typical vegetation fires on September 1992 in Brazil, using remote sensing. Airborne measurements at $200 \mathrm{~m}$ a.g.l. in the main plume from fires burning tropical savanna showed vertical velocities up to $5 \mathrm{~m} \mathrm{~s}^{-1}$ and potential air temperature as much as $4 \mathrm{~K}$ greater than that of the environmental air. The estimated plume area was 59 ha, encompassing an instantaneous total sensible heat flux around $0.87 \mathrm{GW}$, and the plume extended through the $1.6 \mathrm{~km}$ depth of the planetary boundary layer (PBL). For the Serra do Maranhão fire (involving grassland, cerrado and gallery forests) the primary plume extended through a depth of $4.3 \mathrm{~km}$, producing a capping cumulus that peaked at an altitude of $5.1 \mathrm{~km}$. At $1.3 \mathrm{~km}$ a.g.l. the plume area was estimated as 43 ha and the total sensible heat flux around $1.4 \mathrm{GW}$. In addition, airborne measurements were done within plumes from fires burning slashed tropical forest in Marabá, also in Brazil. This case showed strong vertical velocity with a peak of $15.4 \mathrm{~m} \mathrm{~s}^{-1}$ and potential air temperature as much as $2.4 \mathrm{~K}$ greater than in the ambient air at $526 \mathrm{~m}$ a.g.l. The estimated plume area was 93 ha with a total of $6.7 \mathrm{GW}$ of sensible heat flux. This plume was also capped by a deep cumulus.

In this paper we describe the implementation of the plume rise sub-grid scale transport term in the Coupled Aerosol and Tracer Transport model to the Brazilian developments on the Regional Atmospheric Modeling System (CATT-BRAMS, Freitas et al., 2005) 3-D atmospheric transport model. This transport mechanism is simulated by embedding a 1-D cloudresolving model, with appropriate lower boundary conditions, in each column of CATT-BRAMS, the host model. The paper is organized as follows. In Sect. 2, the methodology is described. Numerical sensitivity studies are discussed in Sect. 3. Section 4 explores model results for the Quinault prescribed fire. The CATT-BRAMS model simulations for 2002 are introduced and comparisons of model results with aircraft CO profiles from the SMOCC 2002 (Smoke Aerosols, Clouds, Rainfall and Climate) and CO data retrieved by the "Measurements of Pollution in the Troposphere" (MOPITT) instrument, onboard the Earth Observing System (EOS)/Terra satellite, are presented in Sect. 5. Our conclusions are discussed in Sect. 6.

\section{Methodology}

Biomass burning emits hot gases and particles which are transported upward with the positive buoyancy of the fire. 
Due to radiative cooling and the efficient heat transport by convection, there is a rapid decay of temperature above the fire area. Also, the interaction between the smoke and the environment produces eddies that entrain colder environmental air into the smoke plume, which dilutes the plume and reduces buoyancy. The dominant characteristic is a strong upward flow with an only moderate temperature excess above ambient. The final height that the plume reaches is controlled by the thermodynamic stability of the atmospheric environment and the surface heat flux release from the fire. Moreover, if water vapor is allowed to condense, the additional buoyancy gained from latent heat release plays an important role in determining the effective injection height of the plume. However, in presence of strong horizontal wind, it might enhance the lateral entrainment and even prevent the plume to reach the condensation level, particularly for small fires, impacting the injection height. The plume rise mechanism may have a strong impact on pollutant dispersion since in the free troposphere with its higher wind speeds, the pollutants are advected faster away from the source region with higher wind speeds, especially outside the equatorial tropics. Removal processes are also more efficient in the PBL; when the pollutants are transported to the free troposphere their residence time increases (Chatfield and Delany, 1990).

The plume rise associated with the biomass burning is explicitly simulated using a simple one-dimensional timedependent entrainment plume model originally developed by Latham (1994). A simple 1-D model that provides reasonable estimates of parameters needed is required, otherwise the embedded model might easily require more computer time than the 3-D host model. The governing equations are based on the first law of thermodynamics, the vertical equation of motion (Simpson and Wiggert, 1969), and continuity equations for the water phases. Equations (1) to (5) introduce the 1-D cloud-resolving model (CRM) designed for this task:

$$
\begin{aligned}
\frac{\partial w}{\partial t}+w \frac{\partial w}{\partial z} & =\frac{1}{1+\gamma} g B-\frac{2 \alpha}{R} w^{2}+\frac{\partial}{\partial z}\left(K_{m} \frac{\partial w}{\partial z}\right) \\
\frac{\partial T}{\partial t}+w \frac{\partial T}{\partial z} & =-w \frac{g}{c_{p}}-\frac{2 \alpha}{R}|w|\left(T-T_{e}\right) \\
& +\frac{\partial}{\partial z}\left(K_{T} \frac{\partial T}{\partial z}\right)+\left(\frac{\partial T}{\partial t}\right)_{\text {microphysics }}
\end{aligned}
$$

$$
\begin{aligned}
\frac{\partial r_{v}}{\partial t}+w \frac{\partial r_{v}}{\partial z} & =-\frac{2 \alpha}{R}|w|\left(r_{v}-r_{v e}\right) \\
& +\frac{\partial}{\partial z}\left(K_{T} \frac{\partial r_{v}}{\partial z}\right)+\left(\frac{\partial r_{v}}{\partial t}\right)_{\text {microphysics }}
\end{aligned}
$$

$$
\begin{aligned}
\frac{\partial r_{c}}{\partial t}+w \frac{\partial r_{c}}{\partial z} & =-\frac{2 \alpha}{R}|w| r_{c} \\
& +\frac{\partial}{\partial z}\left(K_{T} \frac{\partial r_{c}}{\partial z}\right)+\left(\frac{\partial r_{c}}{\partial t}\right)_{\text {microphysics }}
\end{aligned}
$$

$$
\begin{aligned}
\frac{\partial r_{\text {ice,rain }}}{\partial t}+w \frac{\partial r_{\text {ice,rain }}}{\partial z} & =-\frac{2 \alpha}{R}|w| r_{\text {ice,rain }} \\
& +\frac{\partial}{\partial z}\left(K_{T} \frac{\partial r_{\text {ice,rain }}}{\partial z}\right) \\
& +\left(\frac{\partial r_{\text {ice,rain }}}{\partial t}\right)_{\text {microphysics }} \\
& + \text { sedim }_{\text {ice, rain }}
\end{aligned}
$$

Here $w, T, r_{v}, r_{c}, r_{\text {rain }}, r_{\text {ice }}$ are the vertical velocity, air temperature, water vapor, cloud, rain and ice mixing ratios, respectively, and are associated with in-cloud air parcels. Entrainment of environmental air is taken to be proportional to the vertical velocity in the cloud, and the entrainment coefficient is based on the traditional formulation $2 \alpha R^{-1}$ where $R$ stands for the radius of the plume and $\alpha=0.1$. In Eq. (1) $\gamma$ is 0.5 and was introduced to compensate for the neglect of non-hydrostatic pressure perturbations (Simpson and Wiggert, 1969), $g$ is the acceleration due the gravity and $B$ is the buoyancy term related to the difference of temperature between the in-cloud air parcel and its environment and includes the downward drag of condensate water. In Eqs. (2) and (3) the index $e$ stands for the environmental value. $c_{p}$ is the specific heat at constant pressure. Cloud microphysical calculations are based on the Kessler (1969) parameterization for accretion and include ice formation according to Ogura and Takahashi (1971). Autoconversion is performed following the Berry (1967) formulation. In our case, the initial number concentration of cloud condensation nuclei is defined as $10^{5} \mathrm{~cm}^{-3}$, as described in Andreae et al. (2004) for pyro-cumulonimbus clouds. These parameterizations provide the microphysical tendencies terms of Eqs. (2) to (5). Sedimentation calculation for ice and rain is performed using the terminal velocity given by Kessler (1969) and Ogura and Takahashi (1971). Scalar fields are advected using a forward-upstream scheme of second-order, with flux limiters to preserve positive definiteness, while for wind a standard leapfrog-type scheme is used (Tremback et al., 1987). $K_{m}$ and $K_{T}$ are the eddy coefficients for the diffusivity of momentum and heat, respectively. They are based on the Smagorinsky (1963) scheme and include corrections for the influence of the Brunt-Vaisala frequency (Hill, 1974) and Richardson number (Lilly, 1962).

The lower boundary condition is based on a virtual source of buoyancy placed below the model surface (Turner, 1973; Latham, 1994). The buoyancy generated by this source is obtained from the convective energy flux $E$ and the plume radius, for which values are derived in the following way. For each grid column, all fires are aggregated into three categories (forest, woody savanna, and grassland) by merging the fire location with the land use dataset. For each category, two heat fluxes (lower and upper limits) are defined according to Table 1 (Freitas et al., 2006, reproduced here for convenience) and using the McCarter and Broido (1965) factor $(0.55)$ to convert heat flux into convective energy. The radius of plume is estimated by the fire size. The remote 
Table 1. Lower and upper bounds for the heat flux $\left(\mathrm{kW} \mathrm{m}^{-2}\right)$ and fraction of biomass consumed in the flaming phase (Freitas et al., 2006).

\begin{tabular}{llll}
\hline Biome type & $\begin{array}{l}\text { Lower bound } \\
\mathrm{kW} \mathrm{m}^{-2}\end{array}$ & $\begin{array}{l}\text { Upper bound } \\
\mathrm{kW} \mathrm{m}^{-2}\end{array}$ & Flaming phase consumption \\
\hline Tropical forest & 30. & 80. & $45 \%$ \\
Woody savanna - cerrado & 4.4 & 23. & $75 \%$ \\
Grassland - pasture - cropland & & 3.3 & $97 \%$ \\
\hline
\end{tabular}

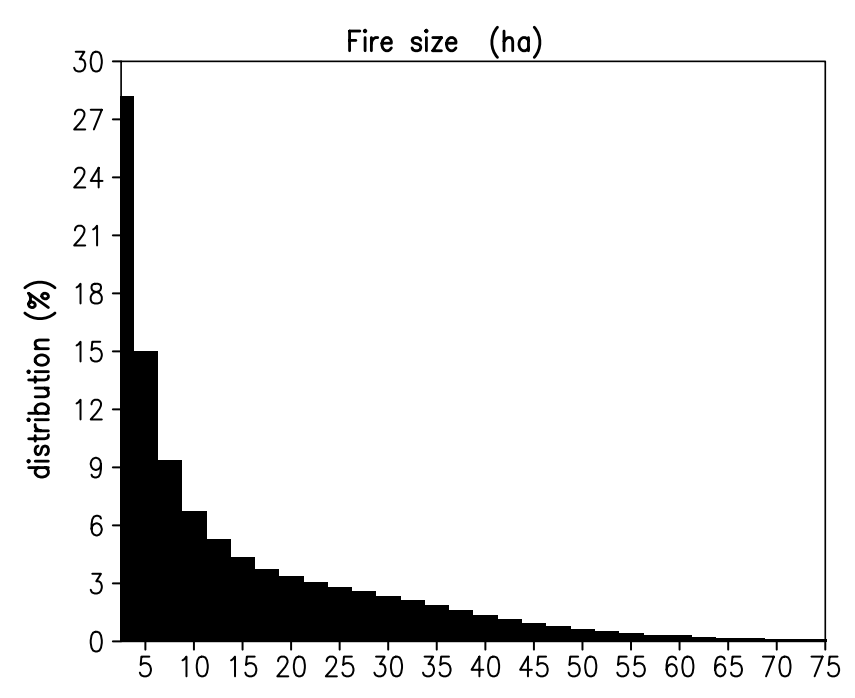

Fig. 1. Fire size distribution as estimated by the WF_ABBA algorithm for the months July to November, 2002. The fire size interval is $2.5 \mathrm{ha}$.

sensing fire product GOES-8 WF_ABBA (Wild Fire Automated Biomass Burning Algorithm, Prins et al., 1998) is used to provide the fire location and the instantaneous fire size for each non-saturated and non-cloudy fire pixel, where it is possible to retrieve sub-pixel fire characteristics. The area of the fire is defined from the simple mean of the instantaneous size, as estimated by WF_ABBA, of all fires that belong to the same category. Figure 1 shows the fire size distribution for 5 months of the burning season (July to November) of 2002, in which 600652 fires were analyzed using 2.5 ha as the size interval. About $28 \%$ of the fires have instantaneous size lower than 2.5 ha and for $75 \%$ of the detected fires, the size is lower than 20 ha. The mean value of entire distribution is 12.8 ha with standard deviation of 14.7 ha. This mean value is used when a specific fire count has not valid information about the instantaneous fire size. With the selected convective energy flux and plume radius the buoyancy flux $F$ is calculated using the following expression (Viegas, 1998)

$F=\frac{g \Re}{c_{p} p_{e}} E R^{2}$ where $\Re$ is the ideal gas constant and $p_{e}$ is the ambient surface pressure. Once the buoyancy flux is determined, it provides the vertical velocity $\left(w_{0}\right)$ and the temperature excess $\left(T_{0}-T_{e, 0}\right)$ for the air parcels at the surface according to (Morton et al., 1956; Latham, 1994)

$w_{0}=\frac{5}{6 \alpha}\left(\frac{0.9 \alpha F}{z_{v}}\right)^{1 / 3}$

$\frac{\Delta \rho_{0}}{\rho_{e, 0}}=\frac{5}{6 \alpha} \frac{F}{g} \frac{z_{v}^{-5 / 3}}{(0.9 \alpha F)^{1 / 3}}$

$T_{0}=\frac{T_{e, 0}}{1-\frac{\Delta \rho_{0}}{\rho_{e, 0}}}$

where $z_{v}=(5 / 6) \alpha^{-1} R$ is the virtual boundary height, and $\Delta \rho_{0}$ is the density difference between in-cloud air parcels and environmental air at the surface. The surface water vapor excess is calculated from the burnt biomass using $0.5 \mathrm{~kg}$ $\mathrm{H}_{2} \mathrm{O}$ per kg dry fuel as emission factor for water (Byram, 1959). The rate by which biomass is consumed $\left(\mathrm{kg} \mathrm{m}^{-2} \mathrm{~s}^{-1}\right)$ is given by $h C^{-1}$ (Alexander, 1982) where $h$ is the heat flux (Table 1), and $C$ is the combustion coefficient, which was estimated as $19.3 \mathrm{MJ} \mathrm{kg}^{-1}$ for Amazon forest (J. C. Santos, 2005, personal communication) and $15.5 \mathrm{MJ} \mathrm{kg}^{-1}$ for savanna (Griffin and Friedel, 1984).

The upper boundary condition is defined by a Rayleigh friction layer with $60 \mathrm{~s}$ timescale, which relaxes wind and temperature toward the undisturbed reference state values. We adopt the Arakawa-C grid and the model grid space resolution is $100 \mathrm{~m}$ with top at $20 \mathrm{~km}$ height. The model timestep is dynamically calculated following the Courant-FriedrichLewy stability criterion, not exceeding $5 \mathrm{~s}$. The microphysics is resolved with time splitting ( $1 / 3$ of dynamic timestep). The heating rate increases linearly in time from 0 to its prescribed value at time equal to $300 \mathrm{~s}$. Typically, the steady state is reached within $50 \mathrm{~min}$, this number being the upper limit of the time integration. The final rise of the plume is determined by the height which the vertical velocity of the in-cloud air parcel is less than $1 \mathrm{~m} \mathrm{~s}^{-1}$.

The 1-D plume model is embedded in each column of the 3-D host model. In this technique, the 3-D model feeds the plume model with the environmental conditions. Since 


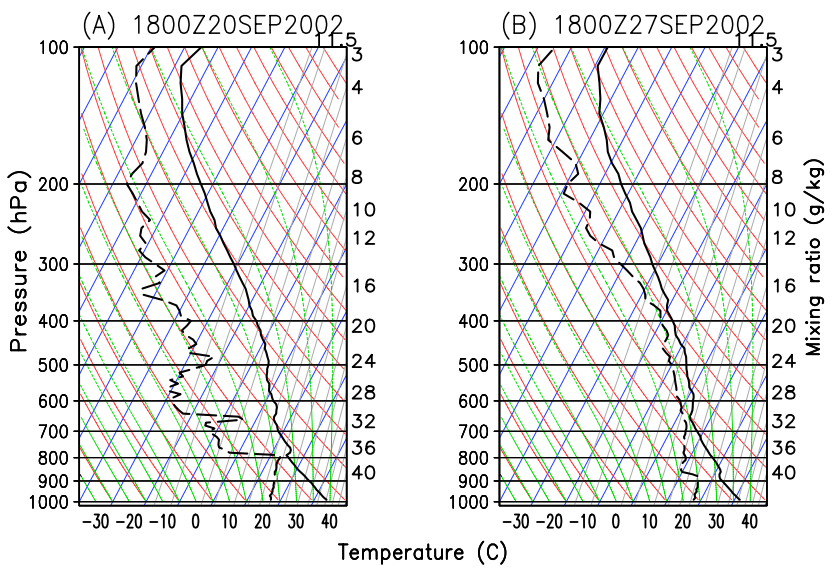

Fig. 2. Temperature (solid) and dew point temperature (dashed) profiles from radiosondes launched in Rondonia $\left(11^{\circ} \mathrm{S}, 60^{\circ} \mathrm{W}\right)$ shown as skew $\mathrm{T}-\log p$ diagrams. Case (a) depicts the condition around 18:00 Z on 20 September 2002, classified as the "dry" case. (b) is the "wet" case corresponding to around 18:00 Z on 27 September 2002.

this technique has been applied to low-resolution 3-D models (grid scale $\sim 30$ to $100 \mathrm{~km}$ ), it has been assumed that the fires have no significant effect on the dynamics and the thermodynamics at this scale. They only affect the source emission field through the height at which, the tracers emitted during the flaming phase are released into the 3-D model. Of course, the absorption of radiative energy by smoke can provide feedbacks on the larger scale, but there is no way to resolve sub-grid inhomogeneities introduced by fresh plumes in this model.

The outline of this technique is:

- A 1-D CRM embedded in each column of the largescale atmospheric-chemistry transport model, and appropriate lower boundary conditions are used.

- For each grid box with fires, the large-scale conditions of the host model are passed to the 1-D CRM.

- The vertical extent of the plume for each fire category and flux energy is resolved explicitly, defining the lower and upper injection height.

- The lower and upper limits of the final rise of the plume are returned to the host model.

- This plume rise is taken into account in the source emission field releasing material emitted during the flaming phase equally in the vertical range delimited by the lower and upper heights.
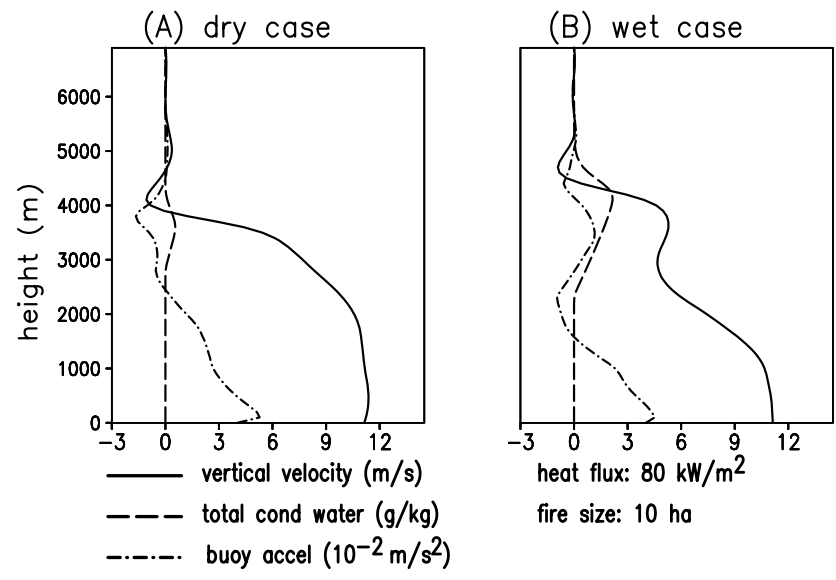

Fig. 3. Model steady state solution for the "dry" and "wet" cases for fires in the forest biome with a heat flux of $80 \mathrm{~kW} \mathrm{~m}^{-2}$ and fire size of 10 ha.

\section{Sensitivity studies}

To evaluate model sensitivity to the fire size and heat flux we performed a set of numerical experiments using two selected thermodynamical situations. Figure 2 shows the two cases for which thermodynamical profiles were obtained from rawinsondes launched during the SMOCC 2002 field campaign in the Amazon Basin (Andreae et al., 2004). Figure 2a depicts a typical condition of the atmosphere over the Amazon basin and central part of South America during the burning season at $1800 \mathrm{Z}$, which is normally the time when the diurnal cycle of the number of fires peaks. The rawinsonde, launched around $1800 \mathrm{Z}$ on 20 September 2002, shows a strong thermal inversion around $800 \mathrm{hPa}$ with a very dry layer above, for which reason we classified this as the "dry" case. On the other hand, the situation described by the rawinsonde launched one week later in the same region (Fig. 2b) is quite different. There was a weaker thermal inversion around $870 \mathrm{hPa}$ and a much moister layer above as compared with the former case. Therefore, this is classified as the "wet" case. Figure $3 \mathrm{a}$ and $\mathrm{b}$ show the model steady state solution for the "dry" and "wet" cases, respectively, for fires in the forest biome with a heat flux of $80 \mathrm{~kW} \mathrm{~m}^{-2}$ and a fire size of $10 \mathrm{ha}$. In both cases, the lower boundary condition provided for vertical velocity, temperature excess and density deficit of the rising air parcel are approximately $11 \mathrm{~m} \mathrm{~s}^{-1}, 5 \mathrm{~K}$ and $2 \%$, respectively.

The vertical velocity $\left(\mathrm{m} \mathrm{s}^{-1}\right)$, total condensate water $\left(\mathrm{g} \mathrm{kg}^{-1}\right)$ and the buoyancy acceleration $\left(10^{-2} \mathrm{~m} \mathrm{~s}^{-2}\right)$ profiles are shown. Because of the lower height of the inversion layer in the "wet" case, the in-cloud air parcels lose vertical velocity faster than in the "dry" case. However, as soon as the air parcels reach the lifting condensation level (LCL), the buoyancy gained by the release of latent heat changes this picture. In the "wet" case, the total condensate water 

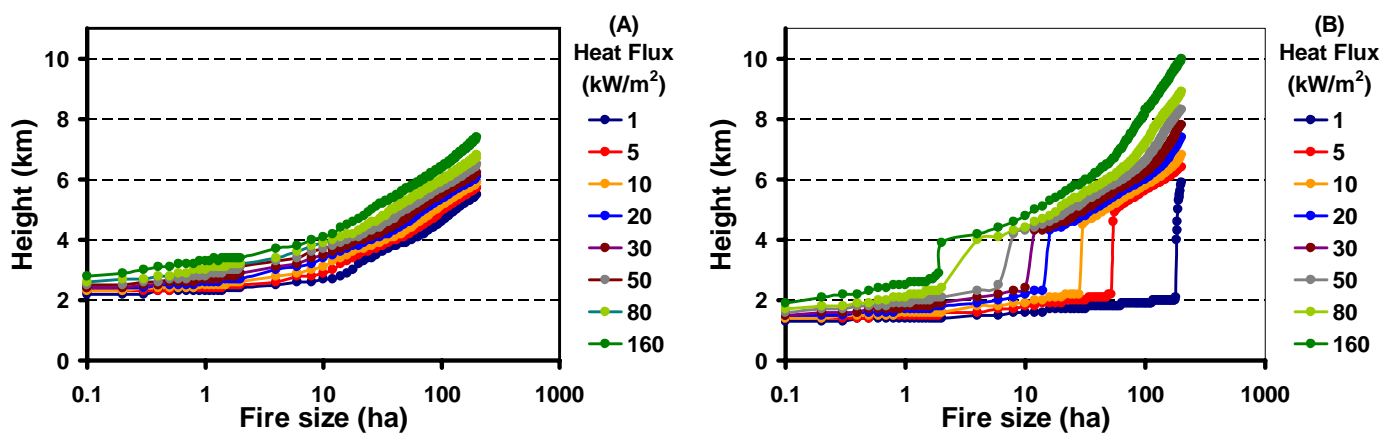

Fig. 4. Effective height (km above surface) reached by plumes from fires with size spanning from 0.1 to 200 ha and heat flux from 1 to $160 \mathrm{~kW} \mathrm{~m}^{-2}$ for the "dry" (a) and "wet" (b) thermodynamical situations. The horizontal axis uses a log scale.

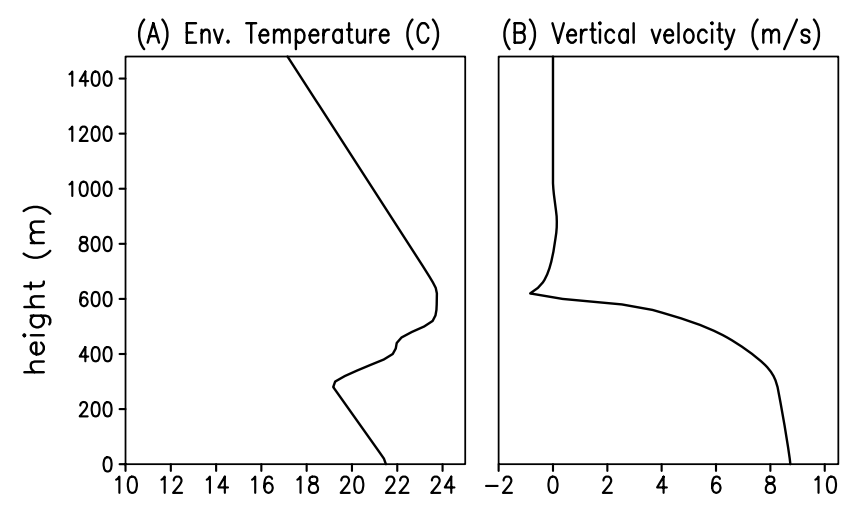

Fig. 5. 1-D plume rise model results for the Quinault prescribed fire. (a) Ambient air temperature $\left({ }^{\circ} \mathrm{C}\right)$ depicting the strong inversion between 300 and $600 \mathrm{~m}$. (b) Steady state profile of the vertical velocity $(\mathrm{m} / \mathrm{s})$.

is greater, as the environmental air entrained by the lateral eddies are much moister, and generates positive buoyancy acceleration, which does not occur in the "dry" case. This imposes a higher plume rise (by about $500 \mathrm{~m}$ ) above the inversion for the wet case. Figure 4 shows the calculation of the final height of the plume as a function of the fire size and heat flux for the "dry" (A) and "wet" (B) cases. Results with fire size spanning from 0.1 to 200 ha and heat flux from 1 to $160 \mathrm{~kW} \mathrm{~m}^{-2}$ are shown. For the "dry" case (Fig. 4a), the model results follow a smooth function with the fire size and heat flux. The results range between 2 and $7.5 \mathrm{~km}$. For a fixed fire size, the variation range of height is 0.5 to $1.5 \mathrm{~km}$. For a fixed heat flux, this range is around 3 to $5 \mathrm{~km}$. However, the "wet" case (Fig. 4b) shows a remarkably different behavior, with discontinuities at the LCL and effective heights spanning from 1.3 to $10 \mathrm{~km}$. This case points out the huge impact of water phase change in the dynamics of the plume. Another important characteristic to observe in the model results for the effective heights is the weak sensitivity to the heat flux over the range we have estimated (Table 1). For the "dry" case, it is possible to express the effective height in terms of the heat flux as height $=a$ (heatflux $)^{b}$, with $a=2.5 \mathrm{~km}$, $b=0.1$ and the correlation coefficient $\left(R^{2}\right) 0.98$ for a fire size of 10 ha. This dependence is weaker than that obtained by Manins (1985) in a stably stratified environment where $a$ and $b$ were estimated as $1.43 \mathrm{~km}$ and 0.25 , respectively. The results for the "dry case" are also consistent with the findings of Heikes et al. (1990), who used a 2-D model applied to slash fires in the Pacific Northwest (USA) under September weather conditions. For fire sizes of 20,38 and 78 ha and a heat flux of about $75 \mathrm{~kW} \mathrm{~m}^{-2}$, the maximum altitudes of plume rise were $2.5,3.2$ and $4.7 \mathrm{~km}$, respectively.

\section{The Quinault fire case}

This section explores the model's performance in simulating the plume rise evolution associated with the Quinault prescribed fire, already introduced in Sect. 1. This fire occurred on 21 September 1994, and it is a very well documented case (T2002 and references therein). According to T2002, the fire lasted a few hours and the maximum estimated heat flux was around $28 \mathrm{~kW} \mathrm{~m}^{-2}$. The height reached by the plume of smoke was around $600 \mathrm{~m}$, being transported horizontally out over the Pacific Ocean. The ambient atmosphere was characterized by a strong temperature inversion between 300 and $600 \mathrm{~m}$, very low relative humidity (less than $40 \%$ ), and nearly calm wind. To verify the 1-D plume model introduced here, it was set up with the above heat flux, a fire size of $19.4 \mathrm{ha}$, and $20 \mathrm{~m}$ grid spacing resolution. The ambient conditions were based on data shown in Fig. 3 of T2002. Figure 5a shows the ambient air temperature, depicting the strong inversion referred to above. The model result for the steady state vertical velocity is shown in Fig. 5b. The vertical velocity of the plume is strongly reduced above $300 \mathrm{~m}$, which reaches a maximum height of about $600 \mathrm{~m}$, consistent with the observations and the ATHAM model results. Unfortunately, T2002 did not present any plume dynamic 
forest

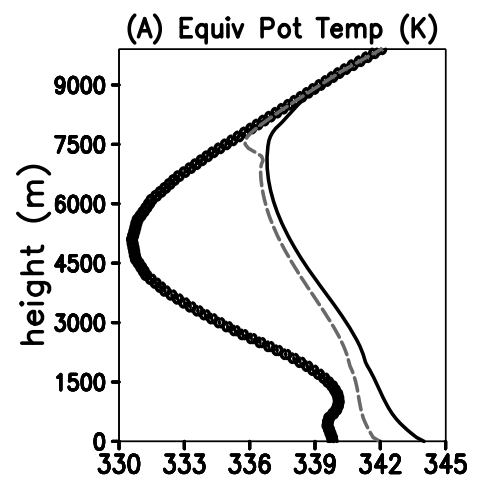

(D) Equiv Pot Temp (K)

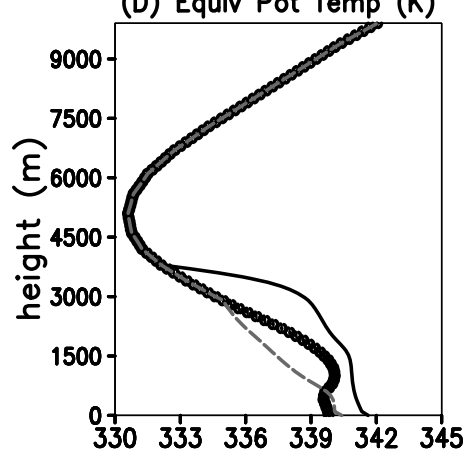

(B) Vertical velocity $(\mathrm{m} / \mathrm{s})$

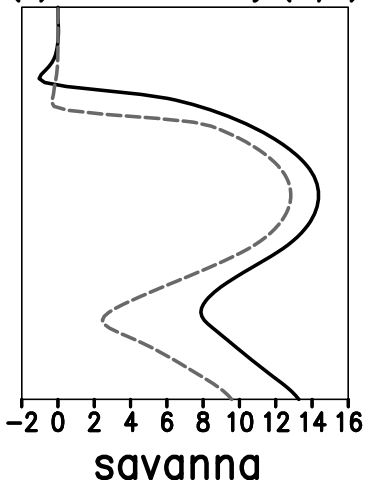

(E) Vertical velocity $(\mathrm{m} / \mathrm{s})$

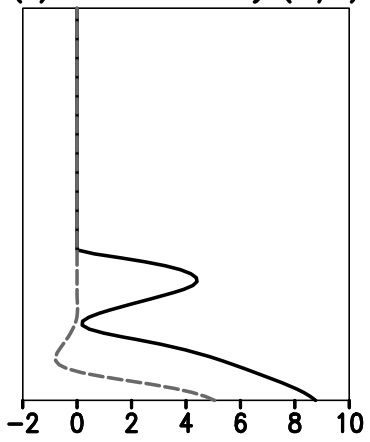

(C) Total cond water $(\mathrm{g} / \mathrm{kg})$

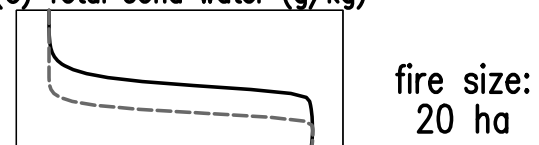

20 ha

heat flux:

$\left(\mathrm{kW} / \mathrm{m}^{2}\right)$

$-80$

$--30$

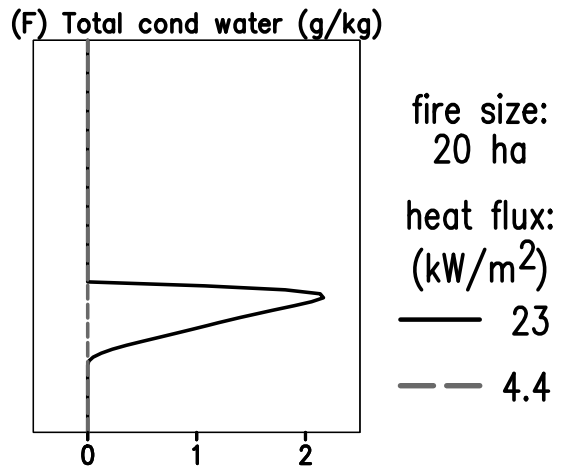

Fig. 6. 1-D plume rise model results for the forest and savanna biomes. The figures show the steady state for the equivalent potential temperature (a, d); vertical velocity (b, e) and total condensate water (c, f) for forest and savanna, respectively. Also for each biome, the results for the upper (solid and black color) and lower bounds (long dash and grey color) of heat flux are shown. Thicker and dark lines show the equivalent potential temperature of the ambient.

characteristics simulated by the ATHAM model and so we could not perform more comparisons between the two models. More thoughful comparisons with the ATHAM results will appear in a forthcoming paper.

\section{Model results and validation using 2002 dry season data}

The 3-D host model used in this study is CATT-BRAMS. BRAMS is based on the Regional Atmospheric Modeling System, RAMS, (Walko et al., 2000) version 5 with several new functionalities and parameterizations. RAMS is a numerical model designed to simulate atmospheric circulation at many scales. RAMS solves the fully compressible non-hydrostatic equations described by Tripoli and Cotton (1982), and is equipped with a multiple grid nesting scheme that allows the model equations to be solved simultaneously on any number of interacting computational meshes of different spatial resolutions. BRAMS features used in this simulation include an ensemble version of deep and shallow cumulus schemes based on the mass flux approach (Grell and
Devenyi, 2002) and soil moisture initialization data (Gevaerd and Freitas, 2006). CATT is a system designed to simulate and study the transport and processes associated with biomass burning emissions. It is an Eulerian transport model fully coupled to the BRAMS. The tracer transport simulation is made simultaneously, or "on-line", with the atmospheric state evolution. The parameterized sub-grid transport includes diffusion in the PBL with a turbulent kinetic energy (TKE) closure. The sub-grid tracer transport by shallow and deep moist convection, which is fully consistent with the convective parameterization, is also taken into account.

Model simulations for the 2002 dry season were performed, and model results were compared with observational data. The model configuration used 2 grids: a coarse grid with $140 \mathrm{~km}$ horizontal resolution covering the South American and African continents, and a nested grid with a horizontal resolution of $35 \mathrm{~km}$, covering only South America. The vertical resolution for both grids was between 150 and $850 \mathrm{~m}$, with the top of the model at $23 \mathrm{~km}$ (42 vertical levels). The integration time was 135 days, starting at $00: 00 \mathrm{Z}$ on 15 July 2002. For atmospheric initial and boundary conditions, 
(A) Equiv Pot Temp (K)
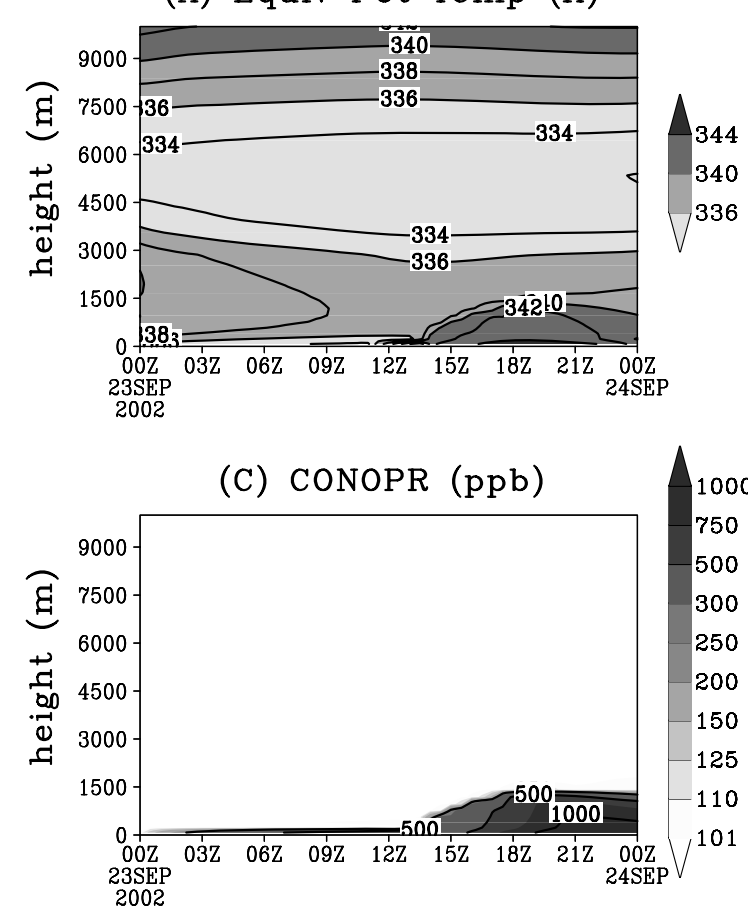

(B) $\mathrm{CO}$ source emission with

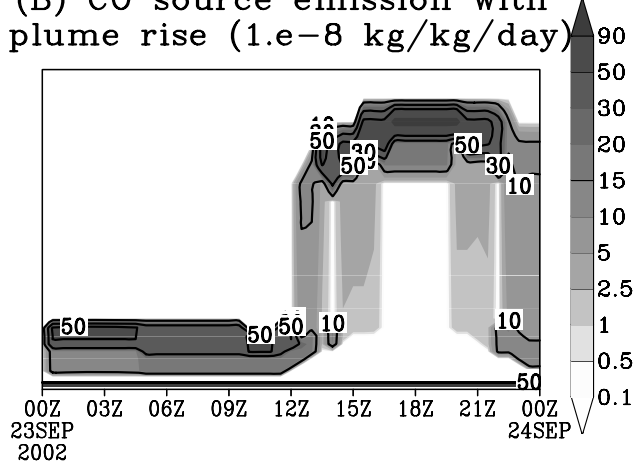

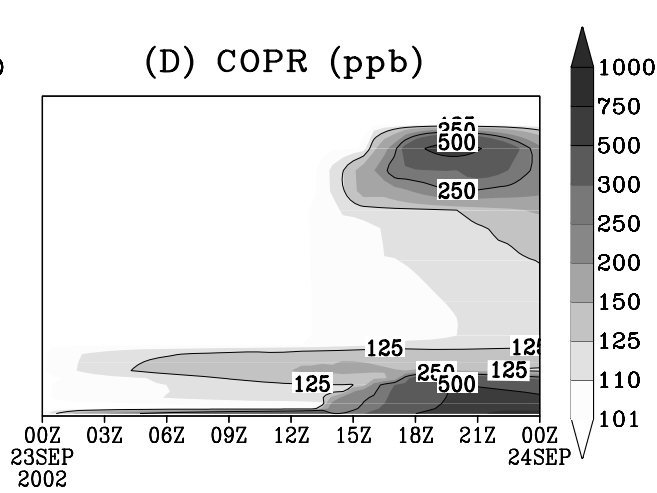

Fig. 7. Diurnal cycle of the (a) equivalent potential temperature, (b) source emission with the plume rise mechanism, the time evolution of the $\mathrm{CO}$ concentration profile for a source emission (c) without this mechanism and (d) with it.

the 6 hourly T126 analysis fields from Center for Weather Forecasting and Climate Studies (CPTEC), Brazil, was used through a nudging type of four-dimensional data assimilation (Davies, 1983) . For most investigations, two tracers were simulated, carbon monoxide (COPR) emitted by a 3$\mathrm{D}$ source that includes the plume rise mechanism, and carbon monoxide (CONOPR), without this mechanism, with all the emissions released in the first model level. The same total mass was emitted for both tracers and they were initialized with the same background values. The total amount of biomass burning emissions was calculated using the Brazilian Fire Emission Model (BFEMO, Freitas et al., 2005). BFEMO emission approach uses detailed information about emission factors, aboveground biomass density and combustion factors for South America biomes as well as fire counts, derived by remote sensing, to determine location and timing of emission. One basic approximation assumed is the fire size retrieved by remote sensing as burnt area to provide an estimation of the amount of biomass consumed by the fire. To determine the type of biome burning and its space and time distribution, the $1 / 2$-hourly WF_ABBA fire product was merged with $1 \mathrm{~km}$ resolution land-use data. The fraction of $\mathrm{CO}$ emitted during the flaming and smoldering phases was estimated using Table 1. Due to the large number of fires and in spite of the fire aggregation procedure, the computational costs required to run this system calling the 1-D plume rise model at each 3-D host model timestep is highly prohibitive. For that reason, we compute and update the effective injection layer only once every hour. Sensitivity tests, not shown, demonstrated good agreement of model results with those obtained by calling the plume rise model at each timestep of the host model.

An example of the results from the plume rise model embedded in CATT-BRAMS is shown in Fig. 6a-f. The figures show the steady state for the equivalent potential temperature (A, D); vertical velocity (B, E) and total condensate water (C, F) for forest and savanna biomes and a fire size of 20 ha at 18:00 Z on 20 September 2002, respectively. Also for each biome, the results for the upper and lower bounds of heat flux, according to Table 1, are shown. In this case, the plume rise dynamics for fires burning forest with heat flux of 80 and $30 \mathrm{~kW} \mathrm{~m}^{-2}$ are similar and define a thin layer of less than $1 \mathrm{~km}$ for the effective injection height. On the other hand, the dynamic evolution in the savanna is very different. With the lower bound value for the heat flux, the plume cannot pass through the stable layer to reach the LCL. Penetration does occur with the upper bound heat flux value for savanna fires, and results in a $3 \mathrm{~km}$ thick injection layer during the flaming phase. 
The Fig. 7 describes the effect of the diurnal cycle of atmospheric stability on the effective injection height for a typical grid box with simultaneous fires in savanna and tropical forest. The Fig. 7a shows the ambient equivalent potential temperature between 0 and $10 \mathrm{~km}$ above the local surface; local time is $4 \mathrm{~h}$ less than UTC. The low level warming resulting from the surface fluxes driven by solar radiation, and the inversion layer just above $6 \mathrm{~km}$ can be seen. The time evolution of the source emission associated with the plume rise mechanism is shown in Fig. 7b. During the night, the atmospheric stability limits the plume rise to an elevation of $2 \mathrm{~km}$ with a $1.5 \mathrm{~km}$ layer thickness. In the afternoon, however, the plume extends upward, reaching a height of $8 \mathrm{~km}$. The upper and denser layer is associated with the forest fires, while the lower, broader, and less dense layer corresponds to the savanna fires, as expected. The effect of the plume rise mechanism on the vertical distribution of emissions is demonstrated in Fig. 7c and d. The diurnal cycle of $\mathrm{CO}$ emitted by a source that does not include the plume rise, CONOPR, is shown in Fig. 7c, while in Fig. 7d the tracer COPR is presented, which includes this mechanism. Without the plume rise, the $\mathrm{CO}$ distribution is shallow and limited to the PBL. The CO distribution of Fig. 7d appears to be more realistic, with the PBL polluted by emissions from the smoldering phase and the lower and mid troposphere polluted by emissions from the flaming phase. An example of the spatial distribution of the $\mathrm{CO}$ source emission (with the plume rise mechanism) is given by Fig. 8, using model results from the coarse grid. It shows a vertical cross section of CO inputs at 18:00 Z on 2 September 2002 along latitude $5.4^{\circ} \mathrm{S}$. The longitude range includes the South American and African continents. The higher and thinner layers of emission in South America are clearly associated with forest fires. In Africa, most fires at this latitude are burning biomes like savanna, which produce broader and lower injection layers, as discussed previously. Model comparison of the horizontal distribution of $\mathrm{CO}$ at $500 \mathrm{hPa}$ with AIRS CO data and two lower tropospheric CO profiles from the SMOCC field campaign were shown in Freitas et al. (2006). The comparison with the AIRS CO demonstrated the huge improvement in model performance close to the sources, as well as in the simulation of long range transport, when the plume rise mechanism was included. In the next sections, we show more comparisons with SMOCC CO data in the lower troposphere and with MOPITT CO data in the whole vertical retrieval domain of this product.

\subsection{Model comparison with SMOCC 2002 CO airborne measurements}

Comparisons of simulated CO profiles in the PBL and lower troposphere with observed data were performed using SMOCC campaign airborne measurements (Andreae et al., 2004). The airborne part of SMOCC took place in the Amazon Basin during September and October of 2002. Carbon monoxide (CO) measurements during SMOCC were ob-

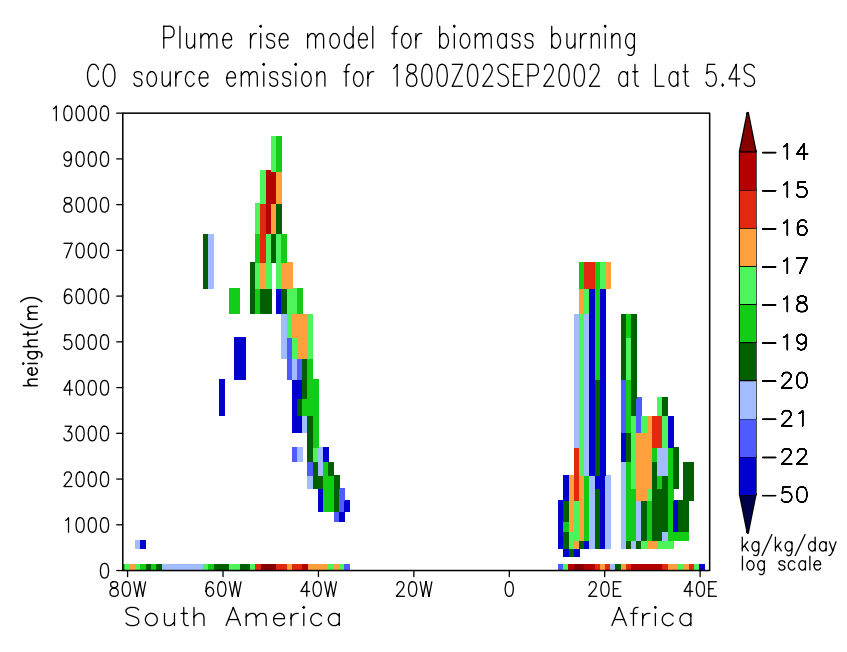

Fig. 8. An example of a vertical cross section of $\mathrm{CO}$ source emission on 18:00 Z on 2 September 2002 at latitude $5.4^{\circ} \mathrm{S}$. The longitude range includes the South American and African continents.

tained on the INPE Bandeirante aircraft using an Aero-Laser (AL5002) instrument operating at $1 \mathrm{~Hz}$. The measurement accuracy is better than $\pm 5 \%$; details can be found in (Guyon et al., 2005). The typical maximum altitude reached by the SMOCC aircraft was $5 \mathrm{~km}$. Haze layers resulting from the detrainment of smoke from convective clouds were visually observed at this height level and also well above the aircraft ceiling altitude during almost all flights in the dry season. The role of the plume rise mechanism on CO simulations is shown in this section using five special $\mathrm{CO}$ tracers and the observed SMOCC CO data. The general mass continuity equation for tracers solved in the CATT-BRAMS model is

$$
\begin{aligned}
\frac{\partial \bar{s}}{\partial t}=\underbrace{\left(\frac{\partial \bar{s}}{\partial t}\right)_{\mathrm{adv}}}_{\mathrm{I}} & +\underbrace{\left(\frac{\partial \bar{s}}{\partial t}\right)_{\mathrm{IBL}}^{\mathrm{PBL}} \mathrm{diff}}_{\mathrm{II}}+\underbrace{\left(\frac{\partial \bar{s}}{\partial t}\right)_{\text {deep }}}_{\mathrm{III}} \\
+ & +\underbrace{\left(\frac{\partial \bar{s}}{\partial t}\right)_{\substack{\text { shallow } \\
\text { conv }}}}_{\mathrm{IV}}+\underbrace{Q}_{\mathrm{V}},
\end{aligned}
$$

where $\bar{s}$ is the grid box mean tracer mixing ratio, I represents the 3-D resolved transport term (advection by the mean wind), II is the sub-grid scale diffusion in the PBL, III and IV are the sub-grid transport by deep and shallow convection and, finally, $\mathrm{V}$ is the source term which may or may not include the plume rise mechanism. In this case the simulation was carried out with five $\mathrm{CO}$ tracers according to the following specifications. Three tracers named COAD, COSH and CODP did not include the plume rise mechanism, with the total CO mass (term V) released into the model layer closest to the surface. The transport processes for the tracer COAD included only the terms I and II. COSH included processes I, II and IV, while CODP used I, II and III. Another two 
(A) SMOCC 01
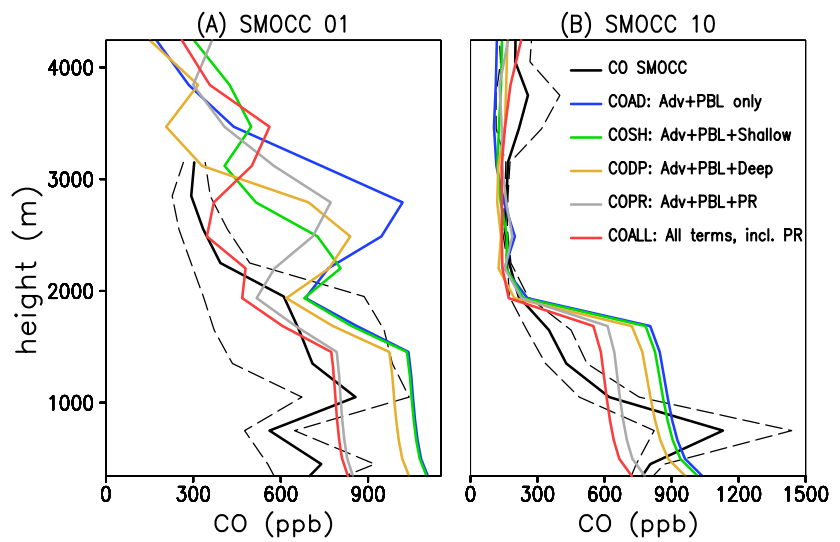

Fig. 9. Comparison between $\mathrm{CO}$ (ppb) observed during SMOCC flights 01 and 10 (black solid line represents the mean while the two long dashed lines show the standard deviation range) and model results. See text for definitions.
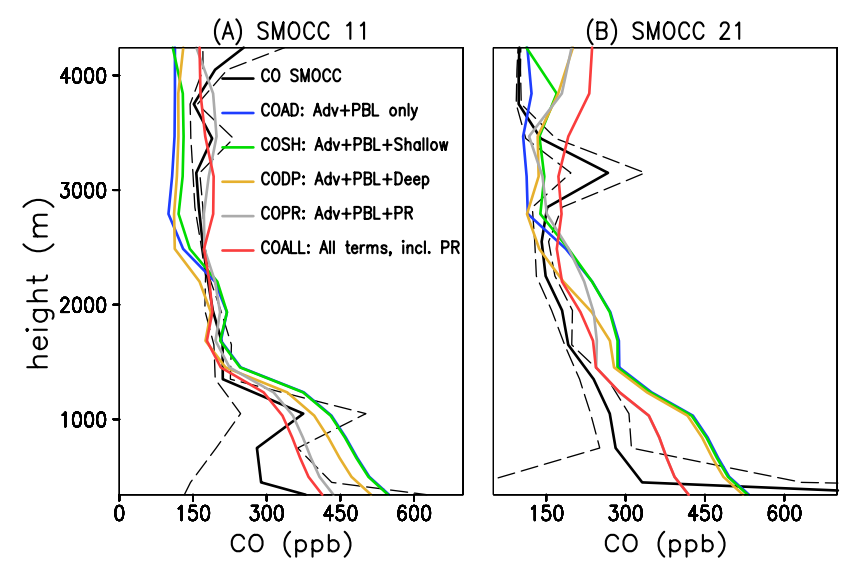

Fig. 10. Comparison between CO (ppb) observed during SMOCC flights 11 and 21 (black solid line represents the mean while the two long dashed lines show the standard deviation range) and model results. See text for definitions.

tracers (named COPR and COALL) included the plume rise mechanism, with the smoldering fraction of the total emission released in the first model layer and the flaming fraction released at the effective injection height provided by the 1$\mathrm{D}$ plume rise model (term $\mathrm{V}$ ). The mixing ratio of COPR was obtained using only the transport terms I and II, while COALL included all I, II, III and IV transport mechanisms.

Figures 9, 10 and 11 show comparisons for several flights. The mean and standard deviations (STD) of the observed CO profiles are shown; note that STD represents the actual variability of the concentrations, not the measurement error. For flight 01 (Fig. 9a) the observed CO profile shows a mean concentration of around $750 \mathrm{ppb}$ from the surface to $2000 \mathrm{~m}$, decreasing to ca. $400 \mathrm{ppb}$ at $3200 \mathrm{~m}$, the maximum height for this flight. The model results for COAD, COSH and
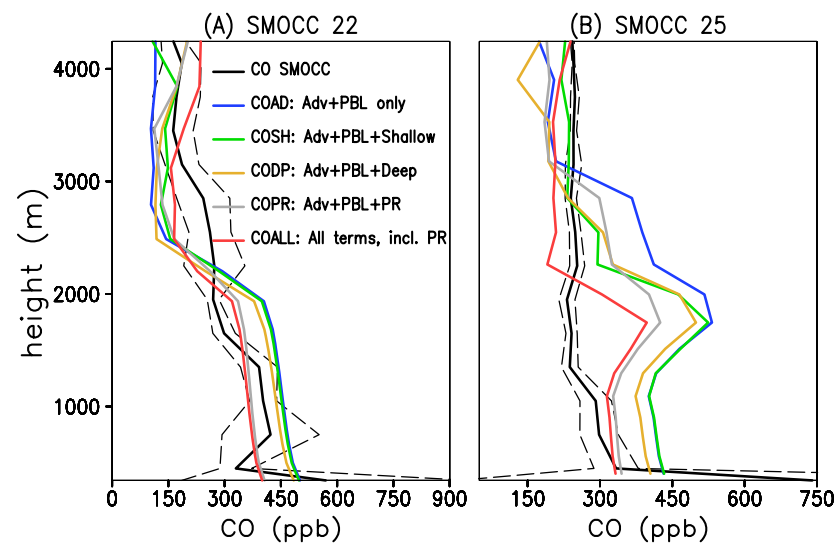

Fig. 11. Comparison between CO (ppb) observed during SMOCC flights 22 and 25 (black solid line represents the mean while the two long dashed lines show the standard deviation range) and model results. See text for definitions.

CODP over-predict CO, especially above the PBL. COPR and COALL agree very well with observations in the first $2 \mathrm{~km}$, and the results from the COALL model are closest to the observed mean. Flight 10 (Fig. 9b) showed strong CO variability in the first $1.2 \mathrm{~km}$ as a result of numerous local fires that injected their plumes in the boundary layer. PBL concentrations outside of these plumes were not well sampled, but ranged around $600-800 \mathrm{ppb}$. In this case, the COPR and COALL model results underestimate the mean observed concentrations below $1 \mathrm{~km}$, but agree well with the regional PBL background of 600-800 ppb. Obviously, the model was not able to capture the very local fire plumes that were intercepted by the aircraft. It also seems that the model simulates a very high and well mixed PBL in this case, which does not agree well with the observed boundary layer height of about 1300-1400 m. Probably, boundary layer development was suppressed regionally because of the very dense smoke over the study region (Longo et al., 2006), however the sampling condition might be also considered. COAD, $\mathrm{COSH}$, and COPR appear to agree well with observations below $1 \mathrm{~km}$ and show greater disagreement above this level. The better agreement of these models at low levels is somewhat fortuitous, as it results from a combination of an overestimate in boundary layer thickness and an overestimate in the fraction of the smoke injected into the PBL. For flight 11 (Fig. 10a) the observed CO again shows a high variability inside the PBL $(<1.5 \mathrm{~km})$ associated with local plumes, which cannot be resolved by the model. Above the PBL and below $3 \mathrm{~km}$ there was relatively clean layer, with only a minor haze layer with about $300 \mathrm{ppb} \mathrm{CO}$. However, above $3 \mathrm{~km} \mathrm{CO}$ starts to increase with height, reaching around $350 \mathrm{ppb}$ at about $4.5 \mathrm{~km}$. Model COPR and COALL agree very well with the observed $\mathrm{CO}$ profile, being inside the variability range in the PBL, and following very closely the $\mathrm{CO}$ distribution 


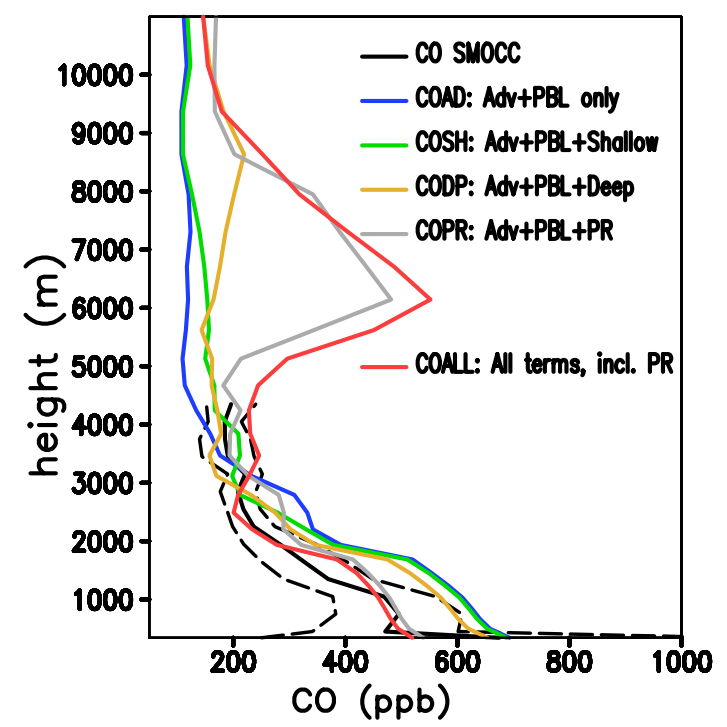

Fig. 12. Comparison between the mean $\mathrm{CO}$ (ppb) observed during SMOCC flights $01,10,11,22,24$ and 25 (black solid line) and the mean of model results. See text for definitions.

in the lower troposphere. Models COAD, COSH and CODP over-predict $\mathrm{CO}$ in the PBL, and simulate too clean a lower troposphere. Flights 21, 22 and 25 (Fig. 10b, Fig. 11a, b) also show better performance for COALL and COPR when comparing with COAD, COSH and CODP results. Fig. 12 presents the mean $\mathrm{CO}$ observed during SMOCC flights 01, $10,11,22,24$ and 25 , and the mean of model results up to an elevation of $10.8 \mathrm{~km}$. From near the surface up to $4.5 \mathrm{~km}$, the vertical range of aircraft measurements, the results from the COPR and COALL models show the best agreement with observations. Above $4.5 \mathrm{~km}$, the COAD, $\mathrm{COSH}$ and CODP model results are noticeably different from COPR and COALL. The next section discusses the model results including also this range of troposphere.

\subsection{Model comparisons with MOPITT CO data}

The role of the plume rise mechanism in CO simulations including the mid and upper-troposphere is shown in this section, using the five $\mathrm{CO}$ tracers that were already introduced in Sect. 5.1 and MOPITT data for October 2002. The MOPITT data used here comprise the tropospheric $\mathrm{CO}$ mixing ratio (ppb) retrievals for 7 pressure levels, from the surface to $150 \mathrm{hPa}$ (Deeter et al., 2003). Because the MOPITT data product shows large horizontal areas without valid data, the model results and MOPITT data were time-averaged over the month of October, and area-averaged over the domain bounded by $25^{\circ} \mathrm{S}$ and the Equator, $72^{\circ} \mathrm{W}$ and $45^{\circ} \mathrm{W}$, the primary region disturbed by the biomass burning activities in South America. Figure 13a shows the comparison between CO retrieved by MOPITT and model results after ap-
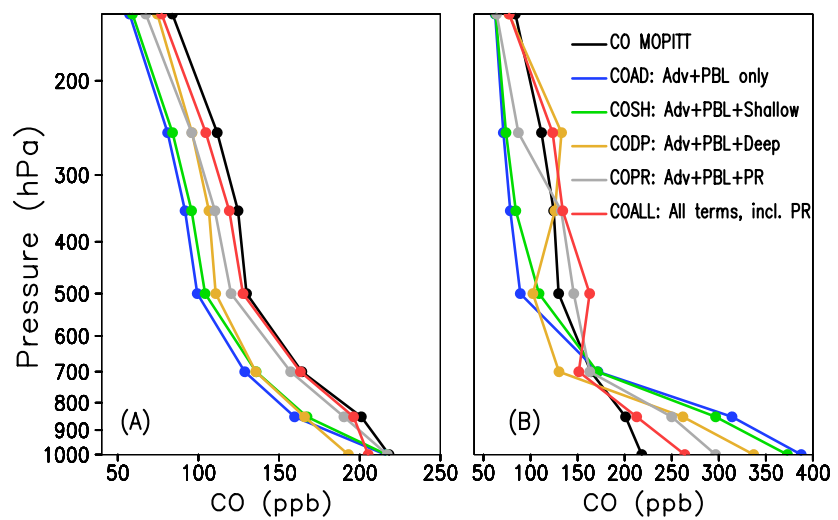

Fig. 13. Comparison between $\mathrm{CO}(\mathrm{ppb})$ retrieved by MOPITT (black lines) and model results with (a) and without (b) the averaging kernel and a priori data $<50 \%$. See text for definitions.

plying the averaging kernel and a priori data $<50 \%$. Because the application of the MOPITT averaging kernels changes the original model results, the unmodified model results are shown in Fig. 13b to clarify the role of the different transport mechanisms described in the previous section. Model results (Fig. 13a) for the tracer COAD show large disagreement with MOPITT CO and the reason is clearly seen in Fig. 13b: the total lack of any sub-grid scale convective transport results in a heavily polluted PBL and a very clean free troposphere above. Including shallow convection transport (COSH) produces only small changes in the results, consistent with what can be expected. Deep convection transport (CODP) yields more realistic upper troposphere $\mathrm{CO}$ simulations, but is not adequate for the correct description of $\mathrm{CO}$ in the PBL and lower troposphere. The plume rise mechanism (COPR) provides much better results for $\mathrm{CO}$ in the PBL and the lower and middle troposphere. However, only when all three main vertical transport mechanisms - shallow and deep moist convection and the pyro-convection (dry or moist) induced by vegetation fires - are included, optimal agreement with the MOPITT CO retrieval is obtained in our comparisons.

\section{Conclusions}

We have shown the usefulness of including the sub-grid scale transport associated with convection resulting from the initial strong buoyancy of gases/aerosols emitted during vegetation fires. Comparison of the results from the complete model with observed $\mathrm{CO}$ and with modeled $\mathrm{CO}$ without the plume rise mechanism demonstrated clearly the importance of this mechanism on the simulation of $\mathrm{CO}$ across the whole troposphere, including the PBL. Without the plume rise mechanism, the simulated free troposphere over the Amazon basin during the burning season is very clean, while the $\mathrm{CO}$ in the PBL is overestimated, a characteristic which 
is not in agreement with observed and remote sensing derived data. Including deep and shallow moist convection and pyro-convection lets the model results come to much closer agreement with locally observed or remotely retrieved $\mathrm{CO}$ measurements.

The uncertainty in the injection height associated with the uncertainty of the fire size and heat flux are expected to not affect significatively the smoke distribution in the 3-D model because it is typically of the order of 1-3 vertical layers of the 3-D transport model at that levels (above boundary layer, the thickness of model vertical layers increases from 400 to 850 meters), This in particularly true for a typical dry season situation like that one showed at Fig. 2 (A). On the other side, it is important to emphasize that the plume rise model sensitivity to the environmental thermodynamic is much more significant, like showed at Fig. 7 (B), and, so, it fully justify the choose for an "on-line" and coupled approach of the plume rise model with the 3-D transport model. The methodology presented here provides a powerful and feasible approach to include this mechanism in low resolution atmospheric transport models. The low sensitivity of the final rise of the plume to the heat flux from the fire is an important and desirable feature of the parameterization. Future work will estimate this flux directly from the fire radiative energy obtained by remote sensing. The fire size is another important fire property needed by the model, which may be also provided by remote sensing.

Acknowledgements. We acknowledge partial support of this work by NASA Headquarters (NRA-03-OES-02 and NRA-02-OES-06) and $\mathrm{CNPq}(305059 / 2005-0)$. This work was carried out within the framework of the project "Monitoramento de emissões de queimadas e avaliação das observações de qualidade do ar em Três Lagoas - MS" in collaboration with CENPES/Petrobras; the LBA Smoke, Aerosols, Clouds, Rainfall, and Climate (SMOCC) project (funded by the Environmental and Climate Program of the European Commission under contract No. EVK2-CT-2001-00110SMOCC and by the Max Planck Society), and Radiation, Cloud, and Climate Interactions in the Amazon during the DRY-TO-WET Transition Season (RACCI) project (funded by FAPESP and Instituto do Milenio/LBA/CNPq/MCT).

Edited by: Y. Balkanski

\section{References}

Alexander, M. E.: Calculating and interpreting forest fires intensities, Can. J. Bot., 60, 349-357, 1982.

Andreae, M.: Biomass burning: its history, use and distribution and its impact on environmental quality and global climate, in: Global Biomass Burning: Atmospheric, Climatic and Biospheric Implications, edited by: Levine, J. S., MIT Press, Cambridge, Mass., pp. 3-21, 1991.

Andreae, M., Rosenfeld, D., Artaxo, P., Costa, A., Frank, G., Longo, K. M., and Silva Dias, M A. F.: Smoking rain clouds over the Amazon, Science, 303, 1342-1345, 2004.
Berry, E. X.: Modification of the warm rain process, Preprints, 1st Natl. Conf. on Weather Modification, Am. Meteorol. Soc., Albany, NY, 81-88, 1968.

Byram, G. M.: Combustion of forest fires, in: Forest Fire Control and Use, edited by: Davis, K. P., McGraw-Hill, New York, 1959.

Carvalho Jr., J. A., Santos, J. M., Santos, J. C., Leitão, M., and Niguchi, N.: A tropical rainforest clearing experiment by biomass burning in the Manaus region, Atmos. Environ., 29, 2301-2309, 1995.

Chatfield, R. B., and Delany, A. C.: Convection links biomass burning to increased tropical ozone: However, models will tend to overpredict O3, J. Geophys. Res., 95, 18 473-18 488, 1990.

Clark, T. L., Jenkins, M. A., Coen, J. and Packham, D.: A coupled atmosphere-fire model: Convective feedback on fire-line dynamics, J. Appl. Meteorol., 35, 875-901, 1996.

Clark, T. L., Griffiths, M., Reeder, M. J. and Latham, D.: Numerical simulations of grassland fires in the Northern Territory, Australia: A new subgrid-scale fire parameterization, J. Geophys. Res., 108(D18), 4589, doi:10.1029/2002JD003349, 2003.

Davies, H. C.: Limitations of some common lateral boundary schemes used in regional NWP models, Mon. Wea. Rev., 111, 1002-1012, 1983.

Deeter, M. N., Emmons, L. K., Francis, G. L., Edwards, D. P., Gille, J. C., Warner, J. X., Khattatov, B., Ziskin, D., Lamarque, J.-F., Ho, S.-P., Yudin, V., Atti, J.-L., Packman, D., Chen, J., Mao, D., Drummond, J. R.: Operational carbon monoxide retrieval algorithm and selected results for the MOPITT instrument, J. Geophys. Res., 108(D14), 4399, doi:10.1029/2002JD003186, 2003.

Freitas, S. R., Longo, K. M., Silva Dias, M., Silva Dias, P., Chatfield, R., Prins, E., Artaxo, P., Grell, G., and Recuero, F.: Monitoring the transport of biomass burning emissions in South America, Environmental Fluid Mechanics, doi:10.1007/s10652-0050243-7, 5(1-2), 135-167, 2005.

Freitas, S. R., Longo, K. M., and Andreae, M. O.: Impact of including the plume rise of vegetation fires in numerical simulations of associated atmospheric pollutants, Geophys. Res. Lett., 33, L17808, doi:10.1029/2006GL026608, 2006.

Fromm, M., Alfred, J., Hoppel, K., Hornstein, J., Bevilacqua, R., Shettle, E., Servranckx, R., Li, Z., and Stocks, B.: Observations of boreal forest fire smoke in the stratosphere by POAM III, SAGE II, and lidar in 1998, Geophys. Res. Lett., 27, 14071410, 2000.

Fromm, M. and Servranckx, R.: Transport of forest fire smoke above the tropopause by supercell convection, Geophys. Res. Lett., 30, 1542, doi:10.1029/2002GL016820, 2003.

Gevaerd, R. and Freitas, S. R.: Estimativa operacional da umidade do solo para iniciação de modelos de previsão numérica da atmosfera. Parte I: Descrição da metodologia e validação, Revista Brasileira de Meteorologia, 21(3), 1-15, 2006.

Grell, G. and Devenyi, D.: A generalized approach to parameterizing convection combining ensemble and data assimilation techniques, Geophys. Res. Lett., 29(14), doi:10.1029/2002GL015311, 2002.

Griffin, G. F. and Friedel, M. H.: Effects in fire in Central Australia rangelands. I - Fire and fuel characteristics and change in herbage and nutrients, Aust. J. Ecol., 9, 381-393, 1984.

Grishin, A. M.: Mathematical modelling of forest fires, in: Fire in Ecosystems of Boreal Eurasia, edited by: Goldammer, J. G. and Furyaev, V. V., Kluwer Acad., Norwell, Mass., pp. 285-302, 
1996.

Guyon, P., Frank, G. P., Welling, M., Chand, D., Artaxo, P., Rizzo, L., Nishioka, G., Kolle, O., Fritsch, H., Silva Dias, M. A. F., Gatti, L. V., Cordova, A. M., and Andreae, M. O.: Airborne measurements of trace gases and aerosol particle emissions from biomass burning in Amazonia, Atmos. Chem. Phys., 5, 29893002, 2005, http://www.atmos-chem-phys.net/5/2989/2005/.

Heikes, L., Ransohoff, L., and Small, R.: Numerical simulation of small area fires, Atmos. Environ., 24A, 297-307, 1990

Hill, G. E.: Factors controlling the size and spacing of cumulus clouds as revealed by numerical experiments, J. Atmos. Sci., 31, 646-673, 1974.

Jost, H., Drdla, K., Stohl, A., et al.: In-situ observations of midlatitude forest fire plumes deep in the stratosphere, Geophys. Res. Lett., 31, L11101, doi:10.1029/2003GL019253, 2004.

Kaufman, Y.: Remote sensing of direct and indirect aerosol forcing, in: Aerosol Forcing of Climate, edited by: Charlson, R. J. and Heintzenberg, J., John Wiley \& Sons Ltd, Chichester, 297-332, 1995.

Kessler, E.: On the distribution and continuity of water substance in atmospheric circulation models, Meteor. Monographs, 10, Am. Meteorol. Soc. Boston, MA, 1969.

Latham, D.: PLUMP: A one-dimensional plume predictor and cloud model for fire and smoke managers, General Technical Report INT-GTR-314, Intermountain Research Station, USDA Forest Service, Nov, 1994.

Lavoué, D., Liousse, C., Cachier, H., Stocks, B. J., and Goldammer, J. G.: Modeling of carbonaceous particles emitted by boreal and temperate wildfires at northern latitudes, J. Geophys. Res., 105, 26871-26890, 2000.

Lilly, D. K.: On the numerical simulation of buoyant convection, Tellus, XIV, 2, 148-172, 1962.

Liousse, C., Penner, J. E., Chuang, C., Walton, J. J., Eddleman, H., and Cachier, H.: A global three-dimensional model study of carbonaceous aerosols, J. Geophys. Res., 101(D14), 19411$19432,1996$.

Longo, K. M., Freitas, S. R., Silva Dias, M., Silva Dias, P.: Numerical modelling of the biomass-burning aerosol direct radiative effects on the thermodynamics structure of the atmosphere and convective precipitation. In: International Conference on Southern Hemisphere Meteorology and Oceanography (ICSHMO), 8., Foz do Iguaçu, Proceedings, São José dos Campos: INPE, CDROM, ISBN 85-17-00023-4, p. 283-289, 2006.

Luderer, G., Trentmann, J., Winterrath, T., Textor, C., Herzog, M., Graf, H.-F., and Andreae, M. O.: Modeling of biomass smoke injection into the lower stratosphere by a large forest fire (Part II): sensitivity studies, Atmos. Chem. Phys., 6, 5261-5277, 2006, http://www.atmos-chem-phys.net/6/5261/2006/.

Manins, P. C.: Cloud heights and stratospheric injections from a thermonuclear war, Atmos. Environ., 19, 1245-1255, 1985.

McCarter, R. and Broido, A.: Radiative and convective energy from wood crib fires, Pyrodinamics, 2, 65-85, 1965.

Morton, R., Taylor, G., and Turner, J.: Turbulent gravitational convection from maintained and instantaneous sources, Proc. Roy. Soc. A, 234, 1-23, 1956.

Ogura, Y. and Takahashi, T.: Numerical simulation of the life cycle of a thunderstorm cell, Mon. Wea. Rev., 99, 895-911, 1971.

Penner, J. E., Haselman Jr., L. C., and Edwards, L. L.: Smoke- plume distribution above large-scale fires: Implications for simulations of "Nuclear Winter", J. Clim. Appl. Meteorol., 25, 1434 1444, 1986.

Poppe, D., Koppmann, R., and Rudolph, J.: Ozone formation in biomass burning plumes: Influence of atmospheric dilution, Geophys. Res. Lett., 25, 3823-3826, 1998.

Prins, E., Feltz, J., Menzel, W., and Ward, D.: An overview of GOES-8 diurnal fire and smoke results for SCAR-B and 1995 fire season in South America, J. Geophys. Res., 103(D24), 31 821$31835,1998$.

Reid, J. S., Koppmann, R., Eck, T. F., and Eleuterio, D. P.: A review of biomass burning emissions part II: intensive physical properties of biomass burning particles, Atmos. Chem. Phys., 5, 799825,2005 , http://www.atmos-chem-phys.net/5/799/2005/.

Riggan, P., Tissell, R., Lockwood, R., Brass, J., Pereira, J., Miranda, H., Miranda, A., Campos, T., and Higgins, R.: Remote measurement of energy and carbon flux from wildfires in Brazil, Ecol. Appl., 14, 3, 855-872, 2004.

Rosenfeld, D., Fromm, M., Trentmann, J., Luderer, G., Andreae, M. O., and Servranckx, R.: The Chisholm firestorm: observed microstructure, precipitation and lightning activity of a pyrocumulonimbus, Atmos. Chem. Phys., 7, 645-659, 2007, http://www.atmos-chem-phys.net/7/645/2007/.

Simpson, J. and Wiggert, S.: Models of precipitating cumulus towers, Mon. Wea. Rev., 97, 471-489, 1969.

Smagorinsky, J.: General circulation experiments with the primitive equations. Part I, The basic experiment, Mon. Wea. Rev., 91, 99164, 1963.

Small, R.D. and Heikes, K.: Early cloud formation by large area fires, J. Appl. Meteorol., 27, 654-663, 1988.

Trentmann J., Andreae, M. O., Graf, H.-F., Hobbs, P. V., Ottmar, R. D., and Trautmann, T.: Simulation of a biomass-burning plume: Comparison of model results with observations, J. Geophys. Res., 107(D2), 4013, doi:10.1029/2001JD000410, 2002.

Trentmann, J., Luderer, G., Winterrath, T., Fromm, M., Servranckx, R., Textor, C., Herzog, M., Graf, H.-F., and Andreae, M. O.: Modeling of biomass smoke injection into the lower stratosphere by a large forest fire (Part I): reference simulation, Atmos. Chem. Phys., 6, 5247-5260, 2006, http://www.atmos-chem-phys.net/6/5247/2006/.

Tremback, C., Powell, J., Cotton, W., and Pielke, R.: The forward in time upstream advection scheme: Extension to higher orders, Mon. Wea. Rev., 115, 540-555, 1987.

Tripoli, G. and Cotton, W.: The Colorado State University threedimensional cloud-mesoscale model. Part I: General theoretical framework and sensitivity experiments, J. Res. Atmos., 16, 185219, 1982.

Turner, J. S.: Buoyancy effects in fluids, Cambridge Univ. Press, Cambridge, 368 pp., 1973.

Turquety, S., Logan, J., Jacob, D., Hudman, R., Leung, F., Heald, C., Yantosca, R., Wu, S., Emmons, L., Edwards, D., and Sachse, G.: Inventory of boreal fire emissions for North America in 2004: the importance of peat burning and pyro-convective injection, J. Geophys. Res., 112, D12S03, doi:10.1029/2006JD007281, 2007.

Viegas, D. X.: Convective processes in forest fires, in: Buoyant Convection in Geophysical Flows, edited by: Plate, E. J., Fedorovich, E. E., Viegas, D. X., and Wyngaard, J. C., Kluwer Aca- 
S. R. Freitas et al.: Including the plume rise of vegetation fires

demic Publishers, AA Dordrecht, The Netherlands, pp. 401-420, 1998.

Walko, R., Band, L., Baron, J., Kittel, F., Lammers, R., Lee, T., Ojima, D., Pielke, R., Taylor, C., Tague, C., Tremback, C., and Vidale, P.: Coupled atmosphere-biophysics-hydrology models for environmental modeling, J. Appl. Meteorol., 39, 6, 931-944, 2000 .
Wang, J., Christopher, S. A., Nair, U. S., Reid, J. S., Prins, E. M., Szykman, J., and Hand, J. L.: Mesoscale modeling of Central American smoke transport to the United States: 1. "Top-down" assessment of emission strength and diurnal variation impacts, J. Geophys. Res., 111, D05S17, doi:10.1029/2005JD006416, 2006. 